\title{
Retraction Note to: Can funding for university partnerships between Africa and the US contribute to social development and poverty reduction?
}

\author{
Christopher S. Collins ${ }^{1}$
}

Published online: 7 May 2015

(C) Springer Science+Business Media Dordrecht 2015

\section{Retraction Note to: High Educ (2014) 68:943-958 \\ DOI 10.1007/s10734-014-9753-x}

This article published in \{Volume 68, Issue 6, pages 943-958, DOI 10.1007/s10734-0149753-x $\}$ has been retracted at the request of the editors in chief, as it contains portions of other author's writings on the same topic, without sufficient attribution to these earlier works. The author of the paper acknowledged that text from background sources was mistakenly used in the Introduction without proper reference to the original source. Specifically, the three first pages of the article (pp. 943-945) contain excerpts of Dr. Felly Chiteng Kot's presentation with the title "Factors Associated with International Partnership Engagement: Results of a Survey of Two African Universities" (pages 3, 8-10) given in ASHE International Forum in Charlotte, North Carolina, 2011, and Dr. Kot's dissertation "Factors Associated with Partnership Experiences, Attitudes, and Perceptions: A Comparative Case Study of Two African Universities" approved by the Graduate School at the University of Minnesota, August 2011, and published by ProQuest/UMI Dissertation Publishing 2011. The author apologizes to the editors and readers as well as the author of the original studies.

The online version of the original article can be found under doi:10.1007/s10734-014-9753-x.

Christopher S. Collins

christopher.s.collins@gmail.com

1 Department of Higher Education, Azusa Pacific University, PO Box 7000, Azusa, CA 91702, USA 